\title{
Limb-girdle muscular dystrophy due to POMK deficiency
}

INSERM

\section{Source}

INSERM. (1999). Orphanet: an online rare disease and orphan drug data base. Limb-girdle muscular dystrophy due to POMK deficiency. ORPHA:445110

Limb-girdle muscular dystrophy due to POMK deficiency is a form of limb-girdle muscular dystrophy presenting in infancy with muscle weakness and delayed motor development (eventually learning to walk at 18 months of age) followed by progressive proximal weakness, pseudohypertrophy of calf muscles, mild facial weakness, and borderline intelligence. 